\title{
A STUDY ON THE MORPHOMETRIC ANALYSIS OF THE MENTAL FORAMEN IN SOUTH INDIAN DRY ADULT HUMAN MANDIBLES
}

\author{
M Janardhan Rao *1, S Saritha 2 .
}

${ }^{{ }^{1} 1}$ Associate Professor, Department of Anatomy, Kamineni Academy of Medical Sciences and Research Centre, Hyderabad, Telangana, India.

${ }^{2}$ Professor \& HOD, Department of Anatomy, Kamineni Academy of Medical Sciences and Research Centre, Hyderabad, Telangana, India.

\section{ABSTRACT}

Introduction: The mental foramen is located on the anterolateral aspect of the body of the mandible through which the mental nerve and vessels passes. The aim of the present study was to determine the incidence of the shape and direction of the opening of the mental foramen and also to determine the size and location of the mental foramen in south Indian dry mandibles.

Materials and Methods: A total of 140 mental foramina belonging to 70 dry adult human mandibles of south Indian origin were collected. The shape and the direction of the opening of the mental foramen were recorded. The horizontal and vertical diameters of the mental foramen, the distance from the center of the foramen to symphysis and to inferior border of the mandible and the distance between the two mental foramina were measured with digital vernier calipers.

Results: The shape of the mental foramen was oval in $69.28 \%$ and rounded in $30.71 \%$ of mandibles. The average horizontal diameter of the mental foramen was $3.12 \pm 0.43 \mathrm{~mm}$ and $2.99 \pm 0.26 \mathrm{~mm}$ on its right and left sides respectively. The average vertical diameter of the mental foramen was $2.32 \pm 0.31 \mathrm{~mm}$ and $2.21 \pm 0.23 \mathrm{~mm}$ on its right and left sides respectively. The average distance between the two mental foramina were $46.98 \pm 3.23 \mathrm{~mm}$. There was no statistically significant difference between the right and left sides.

Conclusion: The knowledge on the shape, size, and the direction of the opening and the location of the mental foramen is very much useful in dental practice to block the premolar mandibular region for various clinical and surgical procedures.

KEY WORDS: Mental foramen, Nerve block, Mandible, Mental nerve, Dental implants.

Address for Correspondence: Dr M Janardhan Rao, Associate Professor, Department of Anatomy, Kamineni Academy of Medical Sciences and Research Centre, L B Nagar, Hyderabad, Telangana, India. Mobile number: 09030504816, E-Mail: drmjr.kams@gmail.com

\section{Access this Article online}

\section{Quick Response code}

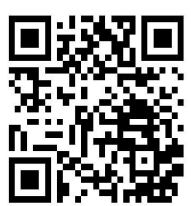

DOI: $10.16965 /$ ijar.2017.404
Web site: International Journal of Anatomy and Research ISSN 2321-4287

www.ijmhr.org/ijar.htm
Received: 10 Aug 2017

Peer Review: 10 Aug 2017

Revised: None
Accepted: 03 Oct 2017
Published (O): 01 Nov 2017
Published (P): 01 Nov 2017

\section{INTRODUCTION}

The Mental foramen (MF) is located on the anterolateral aspect of the body of the mandible. It lies below either the interval between the premolar teeth or below the second premolar tooth. It gives passage to the mental nerve, Mental artery and vein. Mental nerve arises from the inferior alveolar nerve which is a branch of the mandibular nerve. The mental nerve gives sensory nerve supply to the skin and soft tissue over the chin and the labial gingiva of lower teeth. The mental artery is a branch of inferior alveolar artery which is in turn a branch of maxillary artery. It supplies the chin lower teeth and 
gingiva. Mental vein drains into facial vein and finally into pterygoid venous plexus [1]. Morphological variations of the mental foramen are ranging from difference in shape, direction of opening, location to presence of accessory foramen also complete absence of the foramen in some rare cases [2-5].

The recent advances in dentistry increasing the frequency of orthognathic surgeries for various treatments and cosmetic purposes and also the replacement of missing teeth by dental implants have brought the clinical importance to the morphology and morphometry of the mental foramen. Variations of the mental foramen were often remains unnoticed and undiagnosed. To avoid post procedural neurovascular complications in the mental region obtaining the effective mental nerve block is very much essential [6]. The Knowledge on the morphological variations in the shape, the size, and the location of the mental foramen is essential for the dental surgeons as they deals with surgical procedures on the mandible such as the curettage of the premolars, dental implants, root canal treatments, and orthognathic surgeries [7]. Thus the need of the particular attention to the morphology and morphometry of the mental foramen drew us to take up this present study.

Several studies were carried out on the radiographic assessments of the mental foramen using X-ray method which resulted in a high percentage of false negative findings and caused sensory dysfunction due to inferior alveolar nerve damage in this area. The foramen may occasionally misdiagnose with a radiolucent lesion in the apical area of the mandibular premolar teeth. The computerized tomography (CT) is more accurate than the conventional radiographic method for detecting the mental foramen [8]. The present study was carried out on the dry mandibles of south Indian origin to provide the incidence of the morphological variations and the morphometric parameters to locate the mental foramen for various dental and surgical procedures.

\section{MATERIALS AND METHODS}

The present study was carried out on 140 sides of 70 dry adult human mandibles of unknown sex. The damaged, deformed mandibles and the mandibles with resorption at mental foramen were excluded from the study. Shape of the mental foramen and the direction of opening of the mental foramen were observed and noted in all mandibles. To determine the size of the foramen the horizontal and vertical diameters of the foramen were measured with digital vernier calipers. To determine the location of the foramen the mental foramen the following parameters were measured by using vernier calipers. A). The distance from the center of the mental foramen to symphysis menti (SM), the distance from the center of the mental foramen to inferior border (IB) of mandible, and distance between the two mental foramina (Figure 1).

Fig. 1: Showing the morphometric parameters of mental foramen.

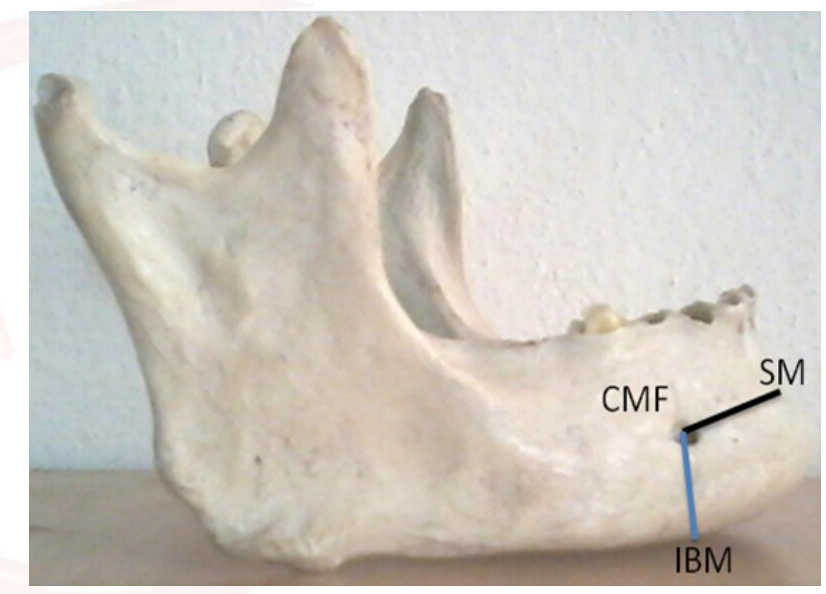

\section{RESULTS}

The shape of the mental foramen was oval in $69.28 \%$ (97 sides) and rounded in $30.71 \%$ (43 sides) (Figure 2). The incidence of the direction of the opening of the mental foramina was reported as $87.85 \%$ (123 sides) posterosuperiorly, $7.14 \%$ (10 sides) superiorly and 5\% (7 sides) antero-superiorly.

Fig. 2: Showing the oval shape mental foramen in $2 \mathrm{~A}$ and round mental foramen in $2 \mathrm{~B}$.

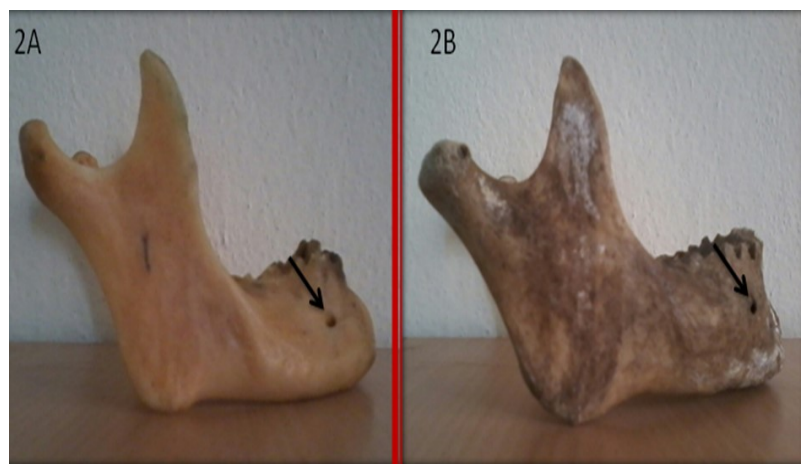


Fig. 3: Showing the distance from the center of the mental foramen to symphysis menti.

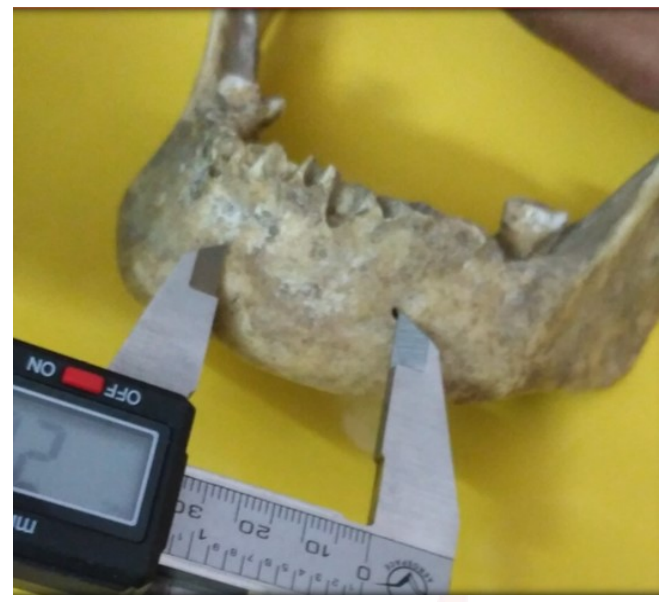

Fig. 4: Showing the distance from the center of the foramen inferior border of the mandible.

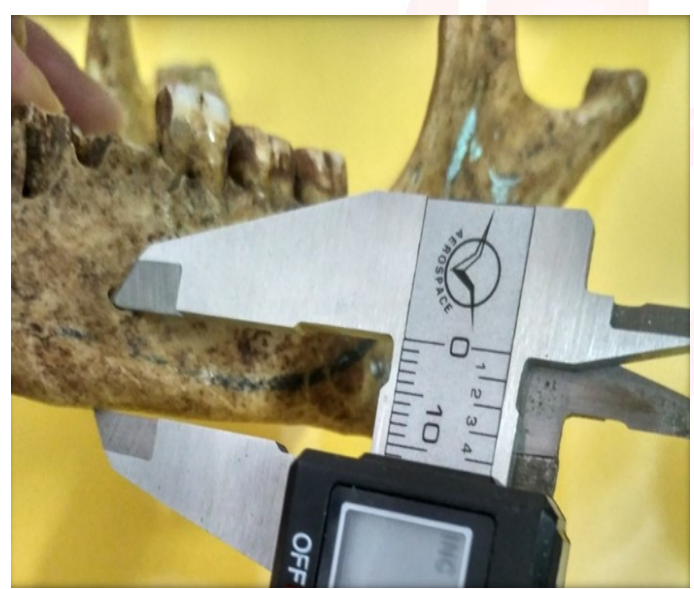

Fig. 5: Showing the distance between the two mental foramina.

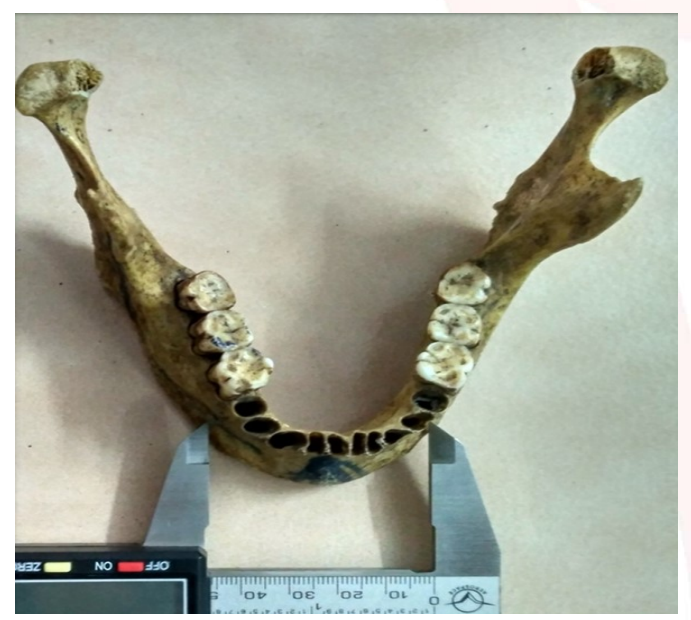

The average horizontal diameter of the mental foramen was $3.12 \pm 0.43 \mathrm{~mm}$ on right side and $2.99 \pm 0.26 \mathrm{~mm}$ on its left side. The average vertical diameter of the mental foramen was 2.32 $\pm 0.31 \mathrm{~mm}$ on its right side and $2.21 \pm 0.23 \mathrm{~mm}$ on its left side. The average distance from the center of the mental foramen to symphysis menti was $28.32 \pm 1.23 \mathrm{~mm}$ on its right side and 27.98 $\pm 1.12 \mathrm{~mm}$ on its left side (Figure 3 ).
The average distance from the center of the mental foramen to inferior border of the mandible was $14.05 \pm 1.05 \mathrm{~mm}$ on its right side and $13.98 \pm 1.12 \mathrm{~mm}$ on its left side (Figure 4). The average distance between the two mental foramina were $46.98 \pm 3.23 \mathrm{~mm}$ (Figure 5). The student's t test was performed to determine the level of significance. There was no statistically significant difference between the right and left sides.

\section{DISCUSSION}

The incidence of the morphological variations of mental foramen and the location varies not only according to age, sex and ethnicity. It may also show variation in different geographic populations belonging to same race. In the present study the shape, the direction of the opening, the size and the location of the mental foramen were studied [9].

The incidence of the shape of the mental foramen was reported as $69.28 \%$ oval and $30.71 \%$ rounded. Oval shape was predominantly observed in the present study which is coinciding with other studies. Ajay Parmar et al., reported the incidence of the shape of the MF as $69 \%$ oval and $31 \%$ rounded in Eastern Indian population and Siddiqui et al., reported the incidence of the shape of the mental foramen as $70 \%$ oval and $30 \%$ rounded in western Indian population. ${ }^{10,11}$ The incidence observed in the present study was contrary to the study of Agarwal et al. where it was reported as $92 \%$ oval foramina and $8 \%$ round foramina in Gujarat population. ${ }^{2}$ Slight variation in the incidence was observed in other ethnic groups where they reported as oval shape in $59 \%$ and rounded in $41 \%$ in Sri lankan population and oval $54 \%$ and rounded $46 \%$ in Tanzania population $[12,13]$.

The incidence of the direction of the opening of the mental foramina was reported as $87.85 \%$ postero-superiorly, $7.14 \%$ superiorly and $5 \%$ antero-superiorly. The posterosuperior direction was predominantly seen which is coinciding with other studies Indian, Sri lankan and Malawians studies $[12,14,15]$.

The size of the mental foramen was determined by measuring the horizontal and vertical diameters. The average horizontal diameter of the mental foramen was $3.12 \mathrm{~mm}$ on right side and 
$2.99 \mathrm{~mm}$ on its left side which was similar to the study by Dipiti A Nimje et al., where they have reported it as $3.11 \mathrm{~mm}$ on right and $3.18 \mathrm{~mm}$ on the left side and also contrary to the study by Udhaya et al., where they reported it as $2.28 \mathrm{~mm}$ on the right and $2.95 \mathrm{~mm}$ on the left side $[7,16]$. The average vertical diameter of the mental foramen was $2.32 \mathrm{~mm}$ on its right side and $2.21 \mathrm{~mm}$ on its left side which was coinciding with the results of Olivera Junior where he reported it as $2.38 \mathrm{~mm}$ and $2.39 \mathrm{~mm}$ on right and left sides respectively [17]. The vertical diameter (Length) and the horizontal diameter (Breadth) of the mental foramen in the African mandibles was $5.66 \mathrm{~mm}$ and $3.97 \mathrm{~mm}$ respectively in males and $4.99 \mathrm{~mm}$ and $3.87 \mathrm{~mm}$ respectively in females which is much higher than the Indians [18].

The average distance from the center of the mental foramen to symphysis menti in the present study was reported as $28.32 \mathrm{~mm}$ and $27.98 \mathrm{~mm}$ on its right and left sides respectively which were much higher than the study by Rahul Rai et al., where they have reported it as $22.41 \mathrm{~mm}$ and $22.23 \mathrm{~mm}$ on its right and left sides respectively [17]. The average distance from the center of the mental foramen to inferior border of the mandible in the present study was reported as $14.05 \mathrm{~mm}$ and $13.98 \mathrm{~mm}$ on its right and left sides respectively which was similar to the study done by Olivera Junior et al. and the average distance between the two mental foramina in the present study was $46.98 \mathrm{~mm}$ [19]. The location of the mental foramen was determined by measuring the distance between the foramen and symphysis menti and the inferior border of the mandible as these two land marks are easily palpable.

\section{CONCLUSION}

The precise knowledge on the incidence of the shape, direction of the opening of the mental foramen and the morphometric parameters of the size and location of the mental foramen would be useful for the dental surgeons to block the mental nerve while performing various clinical and surgical procedures such as the orthognathic surgeries and dental implants.

\section{Conflicts of Interests: None}

\section{REFERENCES}

[1]. Standring S. Gray's Anatomy. 39th ed. London: Elsevier Churchill Livingstone; 2005.

[2]. Agarwal D. R., Gupta S. B. Morphometric analysis of mental foramen in human mandibles of south Gujarat. People's Journal of Scientific Research 2011;4(1):15-18.

[3]. Sawyer, Kiely MI, Pyle Ma. The frequency of accessory mental foramina in four ethnic groups. Arch oral boil. 1998;43:417-20.

[4]. Defreitas V., Mdeira M. C., Tsledofilhs J. L., and Chagas C. F. Absence of the mental foramen in dry human mandible. Acta Anatomica. 1979;104(3):353-355.

[5]. Hasan T., FauziM., and Hasan. Bilateral absence of mental foramen, a rare Variation. International Journal of Anatomical Variations 2010;3:167-169.

[6]. Rakesh Kumar Shukla, Prerna Gupta, Muktyaz Hussein, Fida Hussain, Abhishek Bahadur Singh. Morphometric measurement of mental foramen in dry human mandible in North Indian population. Int J Anat Res 2015;3(1):899-905.

[7]. Udhaya K, Saraladevi KV, Sridhar J. The morphometric analysis of the mental foramen in adult dry human mandibles: A study on the South Indian population. J Clin Diagn Res 2013;7:1547-51.

[8]. Sonick M, Abrahams J, Faiella Ra. A comparison of the accuracy of periapical, panoramic, and computerized tomographic radiographs in locating the mandibular canal. Int. j oral maxillofac implants. 1994;9:455-68.

[9]. Santini A, Land MA. Comparison of the position of the mental foramen in Chinese and British mandibles. Acta. Anat.1990;137(3):208-212.

[10]. Parmar A, Shah K, Patel B, Jadav J, Trivedi B, Kothari G. Morphological and morphometric analysis of mental foramen in dry human mandibles. Int J Med Sci Public Health 2013;2:654-658.

[11]. Siddiqui AU, Daimi SR, Mishra PP, Doshi SS, Date JY, Khurana G. Morphological and morphometric analysis of mental foramen utilizing various assessment parameters in dry human mandibles. Int J Stud Res 2011;1(1):19-22.

[12]. Ilayperma I, Nanayakkara G, Palahepitiya N. Morphometric analysis of mental foramen in adult Srilankan mandibles. Int J Morphol 2009;27(4):1019-24.

[13]. Fabian FM. Position, shape and direction of opening of mental foramen in dry mandibles of Tanzanian adult black males. Ital J Anat Embryol 2007;112(3):169-77.

[14]. Akhilandeswari. B, Priya Ranganath. A study of mental foramina in south Indian dry mandibles. Int J Anat Res. 2016;4(2):2231-2234.

[15]. Igbigbi PS ,Lebona S. The position and dimensions of the mental foramen in adult Malawian mandibles. West Afr J M .2005;24(3):184-189.

[16]. Nimje DA, Wankhede HA, Hosmani PB. Morphometric study of the mental foramen in dry adult human mandibles. Int J Rec Trends Sci Technol 2014;12:479. 
[17]. Oliveira EM Jr, Araújo AL, Da Silva CM, SousaRodrigues CF, Lima FJ. Morphological and morphometric study of the mental foramen on the m-cp- 18 jiachenjiang point. Int J Morphol 2009;27:231-8.

[18]. Souaga K, Adou A, Angoh Y.Topographical and morphological study of the mandibular foramen in black Africans from the Ivory Coast. Odontostomatol. Trop.2004; 27(105):17-21.
[19]. Rai R, Shrestha S, Jha S. Mental foramen: A morphological and morphometrical study. Int J Healthc Biomed Res 2014;2:144-50.

How to cite this article:

M Janardhan Rao, S Saritha. A STUDY ON THE MORPHOMETRIC ANALYSIS OF THE MENTAL FORAMEN IN SOUTH INDIAN DRY ADULT HUMAN MANDIBLES. Int J Anat Res 2017;5(4.2):45904594. DOI: 10.16965/ijar.2017.404 